\title{
Semiotika Tripartisi Concierto de Aranjuez Bagian I Allegro con Spirito Karya Joaquin Rodrigo
}

\author{
Kustap $^{1}$ \\ Jurusan Musik, Fakultas Seni Pertunjukan, Institut Seni Indonesia Yogyakarta
}

\begin{abstract}
Tripartition Semiotics of Concierto de Aranjuez. Tulisan ini membahas Concierto de Aranjuez Bagian I Allegro con SpiritoKarya Joaquin Rodrigo. Metode diskriptiptif analisis digunakan untuk mengupas masalah ini. Berdasarkan penelitian dapat disimpulkan bahwa makna musikal pada level poietic bagi Rodrigo adalah tidak mudah putus asa, ramai dan bersemangat seperti Allegro con spirito. Dalam level neural, sukat yang stabil bermakna tenang, tonika dimulai dari mayor dan diselesaikan dalam mayor bermakna suasana gembira. Dinamika yang dinamis bermakna semangat dari yang sangat lembu, lembut, kuat, kerasa, hingga keras sekali.
\end{abstract}

Key words: Semiotics, tripartition, Concierto de aranjuez, allegro con spirito.

\section{Pendahuluan}

Semiotika adalah ilmu pengkajian tentang tanda dan segala seluk-beluk yang berhubungan dengan tanda itu (Zoest, 1993:1). Menurut Eco, semiotika adalah sebuah teori dusta atau kebohongan. Eco mengatakan, bila sesuatu tidak dapat digunakan untuk mengungkapkan kebohongan maka sesuatu itu tidak dapat juga mengungkapkan kebenaran (Eco, 1979:7; Piliang, 1999:41).

Penelitian tentang Concierto de Aranjuez ini pernah dilakukan oleh Wadi Afriadi tahun 2001, dengan judul "Analisis Bentuk Musikal Concierto de Aranjuez Untuk Gitar dan Orkestra Karya Joaquin Rodrigo Bagian II" dalam bentuk skripsi. Penelitian ini mendeskripsikan bentuk musikal dari hasil analisis bentuknya. Penelitian berikutnya dilakukan oleh Sri Wahono pada tahun 2007, dengan judul "Adagio dari Concierto de Aranjuez Untuk Gitar dan Orkestra Karya Joaquin Rodrigo menurut Interpretasi Tiga Trikotomi Tanda Semiotika Charles Sanders Peirce", dalam bentuk skripsi. Penelitian ini selanjutnya diterbitkan dalam Resital Jurnal Ilmiah Seni Pertunjukan Volume 8 No. 1-Juni 2007, dengan judul: "Adagio Dari Concierto de Aranjuez Untuk Gitar dan Orkestra Karya Joaquin Rodrigo: dari Perspektif Semiotika”. Penelitian ini menyimpulkan makna dari Concierto de Aranjuez bagian II Adagio. Penelitian tentang semiotika yang lainnya pernah dilakukan oleh Kustap berjudul "Makna Musik Sampeq Dayak Kenyah, Suatu Kajian Semiotik. Penelitian ini ditebitkan dalam Surya Seni Jurnal Penciptaan dan Pengkajian Seni Volume 3 Nomor 1 Februari 2007. Penelitian-penelitian tersebut berbeda dari ulasan ini namun dapat menjadi acuan dalam tinjauan kepustakaan penelitian Concierto de aranjuez bagian I allegro con spirito.

\section{Landasan Teori Semiotika}

Pemahaman tentang Semiotika sebaiknya dimulai dari pemahaman beberapa istilah yaitu istilah semantik, semiologi dan semiotik. Istilahistilah ini semula berasal dari bahasa Yunani sema yang berarti makna tanda (meaning sign) (Tagg, 1999:3). Istilah semantik diciptakan oleh ahli bahasa Perancis Michel Breal pada tahun 1897. Istilah semantik dapat dipergunakan dalam tiga cara: (1) Sesungguhnya bermakna mengkaji perubahan atas makna dalam bahasa, yakni, sejenis pengembangan etymology (etimologi adalah ilmu yang mempelajari asal kata dan bagaimana agar dapat memperoleh akan maknanya); (2) pada umumnya digunakan dalam pengertian yang luas untuk menunjukkan pengkajian atas interpretasi, pesan dan makna, atas sistem komunikasi apa pun, dan pengkajian atas hubungan tanda, simbol dan apa yang digambarkannya; (3) juga digunakan dalam ilmu bahasa, untuk perbedaan menuju ke syntax (ilmu kalimat/sintaksis) -hubungan

1 Alamat korespondensi: Prodi Musik ISI Yogyakarta, jalan Parangtritis Km. 6,5 Sewon Yogyakarta. HP. 0852288856259, e-mail: kustap@hotmail.com. 
formal atas satu tanda ke tanda lainnya tanpa mempertimbangkan maknanya- dan pragmatik atau penggunaan bahasa dalam situasi yang kongkrit.

Semiologi adalah istilah yang diciptakan oleh ahli bahasa dari Swiss yaitu Ferdinand de Saussure. Menurut Saussure, pengertian dasar istilah semiologi adalah sama seperti pada pengertian umum semantik dan semiotika. Saussure mendefinisikan semiologi sebagai pengetahuan yang mengkaji kehidupan atas tanda dalam kerangka kehidupan sosial, sedangkan semiotika adalah istilah yang diciptakan oleh filosof Amerika Charles Sanders Peirce. Menurut Peirce, istilah semiotika menunjuk pada pengkajian atas sistem tanda (sistem simbolik). Lebih lanjut Peirce mengatakan semiotika adalah ilmu pengkajian atas tanda dan simbol, terutama antara penulisan dan pengucapan tanda dan referennya dalam kata fisik maupun kata atas gagasan. Menurut terminologi Peirce, makna adalah hasil dari pemahaman akan tanda-tanda dan hubungan antar tanda tersebut. Dalam artikel yang ditulis oleh Jay Zeman berjudul Pierce's Theory of Sign, lebih lanjut Peirce mengatakan bahwa sesuatu yang mewakili seseorang untuk sesuatu dalam beberapa respek atau kapasitasnya adalah tanda. Tanda menunjukkan seseorang, yakni, diciptakan di dalam pikiran orang tersebut sebagai sebuah persamaan tanda, atau barangkali tanda lebih dikembangkan. Tanda tersebut yang mencipta di dalam pemikiran yang disebut interpretant (penerjemah) atas tanda yang pertama. Tanda mewakili akan sesuatu, yakni objeknya (Zeman, 2003).

Peirce mendefinisikan tanda menjadi tiga (trychotomy) ikon, indeks dan symbol. Trikotomi adalah sebuah analisis tentang esensi atas sebuah tanda yang menuntun kepada sebuah pembuktian bahwa setiap tanda ditentukan oleh objeknya. Hal yang pertama, ketika dikatakan sebuah tanda sebagai ikon, dengan mengambil bagian di dalam karakter atas objek; hal penting kedua, ketika dikatakan sebuah tanda sebagai indeks karena sungguh-sungguh dan dalam kehidupan seseorang dihubungkan dengan objek tunggal; hal penting ketiga, bila dikatakan sebuah tanda sebagai simbol kurang lebih tanda tersebut akan diterjemahkan seperti menunjukkan (denoting) objek. Ketiga hal tersebut merupakan konsekuensi atas suatu kebiasaan (istilah ini digunakan seperti termasuk sebuah kodrat alam) (Chandler, 1994)

Secara ringkas teori trikotomi Peirce dipaparkan dalam artikel berjudul Adagio dari Concierto de Aranjuez untuk Gitar dan Orkestra Karya Joaquin Rodrigo dari Perspektif Semiotika yang ditulis Sri Wahono (2007). Teori ini dimulai dari hubungan segitiga triadik yaitu representamen (tanda/sign), object (objek) dan interpretant. Dari triadik kemudian membentuk perputaran trikotomi tanda. Trikotomi pertama dimulai dari triadik representamen yang membentuk tiga trikotomi yaitu qualisign, sinsign dan legisign. Qualisign adalah tanda yang menunjukan kualitasnya sedangkan sinsign adalah tanda yang menyatakan keberadaan dan eksistensi tanda. Legisign adalah tanda yang menyatakan tentang aturan yang berlaku umum. Trikotomi kedua dimulai dari triadik objek yang membentuk tiga trikotomi icon, index dan symbol (Wahono, 2007:53).

Icon adalah tanda yang memilih kesamaan dengan objeknya. Icon adalah suatu cara ketika penanda (signifier) dirasa seperti menirukan atau imitasi apa yang ditandai (signified): yakni, sebuah potret, film karton, dan lukisan. Tanda ikon menyerupai dengan apa yang diwakilinya (Wahono, 2007:54, Aart van Zoest, 1993: 23-26). Index adalah suatu cara ketika penanda (signifier) tidaklah berubah-ubah tetapi secara langsung dihubungkan dalam beberapa cara secara fisik atau oleh sebab (memiliki hubungan logis dengan apa yang ditunjukkannya) kepada apa yang ditandai (signified), hubungan ini dapat menjadi pengamatan atau kesimpulan yakni "tanda alam" (natural sign) (asap, guntur, jejak kaki, gema), gejala medis, alat ukur (penunjuk arah angin, termometer, jam), "sinyal" (signal) (ketukan pada pintu, telepon yang berdering), penunjuk (suatu penunjuk arah jurusan), rekaman (recording) (sebuah foto, sebuah film, rekaman suara (audiorecorded), dan indeksial kata-kata ("itu", "ini”, "di sini", "di sana”). Tanda indeks adalah indikator suatu kondisi atau fakta (yakni, sakit dada dapat mengindikasikan rasa panas dalam perut; asap pada umumnya mengindikasikan adanya api).

Symbol adalah suatu cara ketika penanda (signifer) tidak menyerupai apa yang ditandai (signiffed) tetapi pada dasarnya berubah-ubah atau semata-mata konvensional, sehingga hubungan- 
nya harus dipahami yakni bahasa secara umum (juga bahasa spesifik, tanda baca, kata-kata, ungkapan dan kalimat), angka-angka, kode morse, rambu lalu lintas, bendera nasional, tanda simbol merupakan suatu hubungan yang berubah-ubah (Wahono, 2007:54; Chandler, 1994; Aart van Zoest, 1993: 23-26). Trikotomi ketiga dimulai dari triadik interpretant yang membentuk trikotomi rheme, dicisign dan argument. Rheme mewakili tanda kemungkinan yang kualitatif, decisign menunjukan fakta, dan argument mewakili pemikiran (Wahono, 2007:55; Aart van Zoest, 1993:29).

Arjan van Baest dan Hans van Driel menulis artikel berjudul The Semiotics of C.S. Peirce Applied to Music A Matter of Belief, merangkum dua pernyataan tentang musik dari Stravinsky dan Hanslick. Stravinsky mengatakan, musik bukanlah kekuatan untuk menyatakan sesuatu apapun, apakah suatu perasaan, suatu sikap pemikiran, suasana hati psikologis, sebuah fenomena alam dan atau yang lainnya. Ekspresi tidak akan pernah sebagai suatu unsur yang menjadi sifat dari musik. Maka bukanlah seperti itu tujuan tentang keberadaannya. Jika, kasusnya selalu hampir seperti itu, musik terlihat sebagai media untuk menyatakan sesuatu, itu hanyalah suatu ilusi, dan bukanlah sebuah kenyataan (Arjan van Baest dan Hans van Driel, 1995). Berikut Hanslick mengungkapkan, pada satu sisi dikatakan bahwa maksud dan objek dari musik adalah untuk menggairahkan emosi -emosi yang menyenangkan; pada sisi lain, emosi dapat dikatakan menjadi subjek permasalahan- bahwa karya musik dimaksudkan untuk menggambarkan sesuatu adalah palsu. (Arjan van Baest dan Hans van Driel, 1995).

Bila Stravinsky dan Hanslick mengatakan bahwa musik bukan merupakan ekspresi akan sesuatu apapun maka menurut Peirce semuanya itu adalah tanda (sign). Pendapat yang berbeda dikemukakan oleh Langer mengatakan bahwa seni adalah kreasi bentuk ungkapan perasaan manusia yang dapat dimengerti (Langer, 1953), sedangkan Merriam mendefinisikan musik adalah bentuk yang bermakna, dan makna tersebut adalah sebuah simbol, sesuatu yang ingin diungkapkan, merupakan objek rasa, yang melalui kecemerlangan strukur dinamikanya dapat mengungkapkan bentuk-bentuk pengalaman yang penting yang tidak dapat diungkapkan melalui bahasa. Perasaan, kehidupan, gerakan dan emosi berhubungan dengan bentuk-bentuk pengalaman yang penting seperti yang telah disebutkan di atas (Merriam, 1967). Selanjutnya Langer mengatakan bahwa bentuk yang bermakna (yang benar-benar memiliki makna) adalah hal yang mutlak pada setiap seni (Langer, 1957). Karya seni atau objek lainnya yang difungsikan sebagai sebuah tanda menunjukkan kepada beberapa kenyataan - apa yang dialaminya, apa yang dipercaya, kapan dan dimana dia tinggal, atau apa yang menghiasi mimpi-mimpinya (Langer, 1953).

Menurut Arjan van Baest dan Hans van Driel bahwa pernyataan tersebut mengungkapkan kontroversi dalam referensi musik, permasalahan apakah musik dapat mengacu pada fenomena keistimewaan musik. Dalam kontroversi ini, terdapat dua kesimpulan: (1) bahwa musik tidak bisa mengacu pada fenomena keistimewaan musik (konsepsi yang otonomi); dan (2) menempatkan musik adalah suatu bahasa yang selalu mengacu pada unsur-unsur keistimewaan musik (konsepsi referensial). Pandangan Stravinsky berada pada pendapat yang pertama. Pernyataannya mengenai ekspresi musik, menunjukkan persamaan luar biasa dengan polemik menurut Hanslick (Arjan van Baest dan Hans van Driel, 1995). Menurut Hanslick keistimewaan musik adalah sifat alaminya yang berisi secara keseluruhan kombinasi bunyi secara artistik. Menurut Hanslick, yang terpenting bukanlah penilaian kualitas keindahan ekspresif pada musik, tapi aspek struktural komposisilah yang membawa unsur estetik pada musik. Esensi musik bukanlah ungkapan perasaan tapi pada bentuknya (form). Hanslick dan Stravinsky mempertimbangkan musik sebagai suatu struktur otonomi yang tidak bisa mengungkapkan sesuatu yang mengacu pada sesuatu. Konsepnya adalah dengan mengesampingkan fakta bahwa orangorang sering mencoba untuk menghubungkan struktur musik tertentu dengan unsur-unsur yang istimewa dalam musik seperti emosi. Hal ini tampaknya mendukung pandangan musik sebagai bahasa referensial.

\section{Semiotika Tripartisi Jean-Jaquez Nattiez}

Semiotika tripartisi dimulai dari pemahaman tentang musik masa kini, yang sering diartikan sebagai sebuah seni/entertainment. Tripartisi 
adalah sebuah definisi fakta sosial yang beragam menurut kultur dan jaman. Menurut Jean Molino, pengertian musik sering dikontraskan dengan bising (noise). Menurut Jean-Jacques Nattiez, seorang musikolog Perancis: Pembatasan antara musik dan bising (noise) dalam definisi budaya menyiratkan bahwa musik dan bising tidak dibeda-bedakan, bahkan dalam sebuah kelompok masyarakat batasan ini tidak selalu atau jarang menjadi suatu konsensus. Bagaimanapun juga tidak ada sebuah budaya dan konsep antar budaya umum yang mendefinisikan apakah musik itu. Dukungan berikutnya oleh seorang ahli ekonomi dari Perancis Jacques Attali dalam bukunya Noise menyebutkan dalam sebuah karya "musical sociology" yang dibuat dengan menampilkan suara gaduh, dianggap dapat memberi kebaikan dan tidak identik dengan bising yang dimaksud (Attali, 2009; Nattiez 1990:47).

Dasar pemikiran Pierce yang berawal dari sign, membentuk triadik, menghasilkan trikotomi, dan dikembangkan oleh Jean Jacques Nattiez dengan teori analisis semiotikanya yang diaplikasikan dalam bidang musik. Nattiez mendefinisikan semiotikanya dengan istilah tripartition (tripartisi) (Nattiez, 1990:10-12), yaitu: poietic, neutral atau trace, dan esthesic. Teori ini dapat digambarkan seperti berikut (Nattiez, 1990:17):

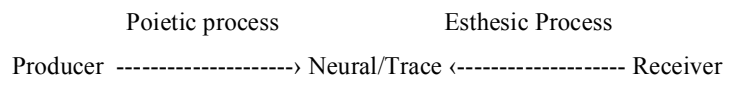

Gambar 1. Proses semiosis tripartisi

Poietic berasal dari bahasa Yunani Poietic yang berarti berhubungan dengan seseorang yang menciptakan karya seni (Mazzola, 2008). Hubungan ini dicontohkan dalam konteks budaya atau dalam suatu kajian produksi seni yang juga dapat terjadi pada musisi atau performing artist misalnya dalam musik jazz, aspek improvisasi adalah hasil asli dalam menciptakan musik. Namun dalam pertunjukan musik klasik sebuah karya musik adalah sebuah perilaku kreatif. Kriteria untuk memutuskan apakah sebuah produksi musik adalah poietic, haruslah merujuk pada sebuah skema/komunikasi dari yang mengirim kepada penerima. Secara singkat dapat disimpulkan bahwa poietic adalah proses mengkaji seluruh aspek produksi sebuah karya, dari saat proses kreatif hingga sampai menuliskan atau mengingatkan kepada lingkungan pergaulan budaya yang mempengaruhi komposer/musisi.

Neutral atau trace adalah perpindahan informasi, secara sederhana direalisasikan oleh score untuk dihubungkan dengan poietic. Neural adalah objek yang telah dibuat oleh pencipta, dan akan dikomunikasikan kepada penerima. Neutral menjadi penilaian data obyektif yang dihubungkan dengan sebuah karya musik. Secara aplikatif poietic adalah berhubungan dengan dirinya sendiri berdasarkan susunan yang tetap, ada dari hasil akhir dari proses poietic, yakni, Score dan/atau buny objek, dan musik itu sendiri.

Esthesic bertugas menguraikan pesan dari penerima, secara sederhana direalisasikan oleh pendengar. Menurut Valéry dalam Mazzola (2008), konsep esthesic telah diciptakan seperti sebuah perbedaan proses estetis dalam teori estetika klasik. Ilmu asal kata (etimologi) ditekankan pada peran penerima yang mengamati karya seni dan mengevaluasinya menurut dirinya sendiri dengan mengkoordinir sistem atas nilai-nilai tertentu. Dapat disimpulkan bahwa esthesic mencakup proses penerimaan akhir atau konsumsi musik, mencakup persepsi, pengamatan, interpretasi dan sejarah. Berikut ini adalah gambaran situasi analisis tripartisi oleh Nattiez (1990:46):

\begin{tabular}{c|c|c}
\hline $\begin{array}{c}\text { Poietic level } \\
\text { (choice of the } \\
\text { composer) }\end{array}$ & $\begin{array}{c}\text { Neural level } \\
\text { (physical definition) }\end{array}$ & $\begin{array}{c}\text { Esthesic level } \\
\text { (Perceptive } \\
\text { judgment) }\end{array}$ \\
\hline \hline \multirow{2}{*}{ musical sound } & $\begin{array}{c}\text { sound of the } \\
\text { harmonic spectrum }\end{array}$ & agreeable sound \\
$\begin{array}{c}\text { noise } \\
\text { (nonmusical) }\end{array}$ & $\begin{array}{c}\text { Noise } \\
\text { (complex sound) }\end{array}$ & $\begin{array}{c}\text { disagreeable } \\
\text { noise }\end{array}$ \\
\end{tabular}

Gambar 2. Situasi analisis tripartisi

Tiga definisi analisis semiotika tripartisi (tripartition) di atas singkatnya terlihat seperti teori komunikasi klasik, sebuah hubungan dari produser (composer/musisi) yang memberi pesan untuk penerima. Namun demikian Nattiez mengatakan bahwa semiotika bukanlah ilmu pengetahuan komunikasi. Menurut Nettiez, dalam analisis semiotika sekurang-kurangnya ada dua hal yang perlu diperhatikan: (1) sebuah analisis kritik komparatif yang menguraikan mengapa karya dapat dijelaskan dengan teori ini, atau menjelaskan gambaran mengenai teori ini atau gambaran tentang penulis tersebut, atau dapat dikatakan bahwa semua analisis adalah sebuah 
representasi; (2) suatu penjelasan kriteria analisis yang digunakan pada analisis yang baru, maka kritik terhadap analisis baru ini bisa diposisikan dalam hubungan dengan analisis, hasil, dan metodenya. Langkah membuat prosedur secara eksplisit akan membantu ke arah menciptakan suatu kemajuan kumulatif dalam pengetahuan dan sebagai konsekuensi kemunculan dari pembahasan analisis yang memuaskan karena lebih bisa dikendalikan (Nattiez, 1990).

\section{Concierto de Aranjuez: bagian I Allegro con Spirito}

Concierto de Aranjuez merupakan karya musik yang dibuat untuk instrumen gitar dan orkestra. Karya ini terdiri dari tiga bagian yang meliputi bagian I yang bertempo Allegro con spirito, bagian II bertempo Adagio dan bagian III bertempo
Allegro Gentile (Rodrigo, 1957:ii). Concierto de Aranjuez bagian I Allegro con spirito akan menjadi fokus dalam penelitian ini. Bagian I Allegro con spirito bersukat $6 / 8$ dan ada satu kali pergantian sukat dari 6/8 menjadi 9/8 terjadi pada birama 163. Jumlah birama dalam bagian I ini mencapai 241 birama. Bagian I Allegro con spirito dimainkan dalam tonika $\mathrm{D}$ mayor.

Bagian I Allegro con spirito, dalam pengolahan orkestrasinya menggunakan instrumen-intrumen dengan urutan sperti berikut: flauto 1,2 dan piccolo; oboe 1,2 dan corno inglise; fogotto 1,2; corno 1,2; tromba 1,2; guitarra solo; violino 1,2; viola; violoncello; dan contrabasso. Berikut ini adalah contoh tampilan full score dari bagian I Allegro con spirito birama 1 sampai dengan birama 3 (Rodrigo, 1957:1):

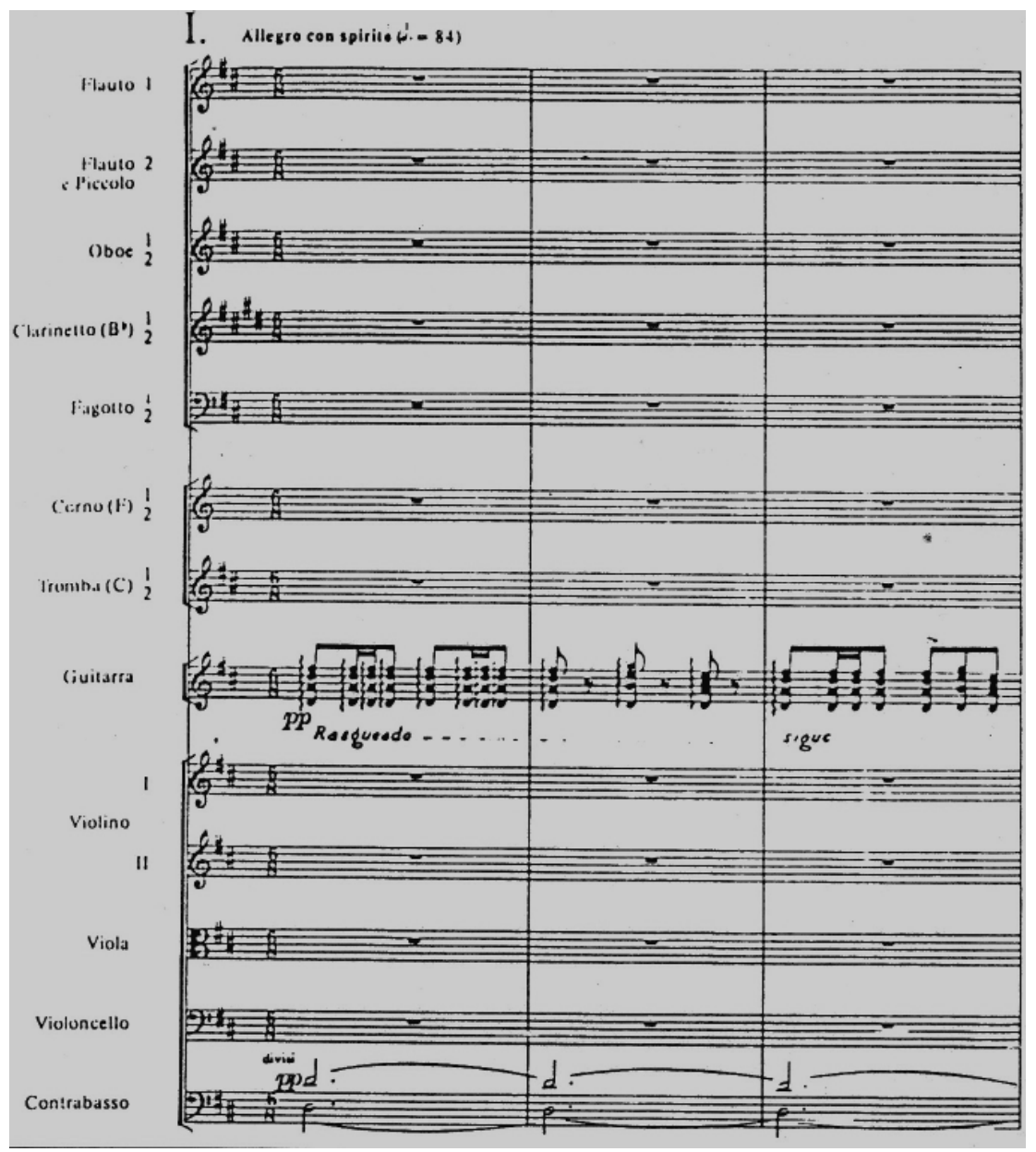

Gambar 3. Score

Concierto de Aranjuez bagian I Allegro con spirito

birama 1 sampai dengan birama 3 
Score Bagian I Allegro conspirito dapat diringkas dengan menunjukan matriks instrumen, birama, sukat, keterangan dan dinamaika. Instrumen diwakili oleh gitar dan orkestra, sukat hanya terdiri dari $6 / 8$ dan satu kali perubahan menjadi 9/8, keterangan menunjuk kepada kejadian, sedangkan dinamika adalah tanda ekpresi, seperti dalam tabel.

\begin{tabular}{|c|c|c|c|c|}
\hline Instrumen & Birama & Sukat & Keterangan & Dinamik \\
\hline Gitar+orkestra & $1 / 1-24 / 1$ & $6 / 8$ & Mulai & $p p$ \\
\hline Gitar & $13 / 1$ & $6 / 8$ & & $f f$ \\
\hline Orkestra & $24 / 2-53 / 3$ & $6 / 8$ & & \\
\hline Gitar+orkestra & $53 / 4-54 / 1$ & $6 / 8$ & & \\
\hline Orkestra & $54 / 2-55 / 3$ & $6 / 8$ & & \\
\hline Gitar+orkestra & $55 / 4-56 / 1$ & $6 / 8$ & & \\
\hline Orkestra & $56 / 2-58 / 6$ & $6 / 8$ & & \\
\hline Gitar+orkestra & $59 / 1-113 / 1$ & $6 / 8$ & & \\
\hline Gitar & $93 / 1$ & $6 / 8$ & & $f f$ \\
\hline Gitar & $99 / 1$ & $6 / 8$ & & $f f$ \\
\hline Gitar & $107 / 1$ & $6 / 8$ & & $f f$ \\
\hline Orkestra & $113 / 2-116 / 6$ & $6 / 8$ & & \\
\hline Gitar+orkestra & $117 / 1-117 / 6$ & $6 / 8$ & & \\
\hline Orkestra & 118/119/6 & $6 / 8$ & & \\
\hline Gitar+orkestra & $120 / 1-120 / 6$ & $6 / 8$ & & \\
\hline Orkestra & $121 / 1-121 / 6$ & $6 / 8$ & & \\
\hline Gitar+orkestra & $122 / 1-122 / 6$ & $6 / 8$ & & \\
\hline Orkestra & $123 / 1-123 / 6$ & $6 / 8$ & & \\
\hline Gitar+orkestra & $124 / 1-162 / 6$ & $6 / 8$ & & \\
\hline Gitar & $124 / 1$ & $6 / 8$ & & $p$ \\
\hline Gitar & $141 / 1$ & $6 / 8$ & & $f$ \\
\hline Gitar & $160 / 1$ & $6 / 8$ & & $f f$ \\
\hline Gitar+orkestra & $163 / 1-163 / 6$ & $9 / 8$ & Perubahan sukat & \\
\hline Orkestra & $164 / 1-167 / 4$ & $6 / 8$ & & \\
\hline Gitar+orkestra & $167 / 5-215 / 1$ & $6 / 8$ & & \\
\hline Gitar & $182 / 1$ & $6 / 8$ & & $f$ \\
\hline Gitar & $186 / 1$ & $6 / 8$ & & $m f$ \\
\hline Gitar & 195/1-195/6 & $6 / 8$ & & cresc. vs decrec. \\
\hline Gitar & 192/1-192/6 & $6 / 8$ & & cresc. \\
\hline Gitar & $197 / 1-197 / 6$ & $6 / 8$ & & cresc. \\
\hline Gitar & 198/1 & $6 / 8$ & & $f$ \\
\hline Gitar & $199 / 6$ & $6 / 8$ & & $m f$ \\
\hline Gitar & $212 / 1$ & $6 / 8$ & & $f f$ \\
\hline Gitar & $215 / 2-217 / 6$ & $6 / 8$ & & \\
\hline Gitar+orkestra & 218/1 & $6 / 8$ & & \\
\hline Orkestra & $218 / 2-229 / 6$ & $6 / 8$ & & \\
\hline Gitar+orkestra & $230 / 1$ & $6 / 8$ & & $f f$ \\
\hline Gitar & $230 / 2-233 / 6$ & $6 / 8$ & & \\
\hline Gitar+orkestra & $234 / 1-238 / 1$ & $6 / 8$ & & \\
\hline Orkestra & $238 / 2-239 / 5$ & $6 / 8$ & & \\
\hline Gitar+orkestra & $240 / 1$ & $6 / 8$ & & \\
\hline Gitar & $240 / 2-240 / 3$ & $6 / 8$ & & \\
\hline Gitar+orkestra & 240/4-241/1 & $6 / 8$ & Selesai & $p p$ \\
\hline
\end{tabular}

\section{Semiosis Tripartisi Concierto de Aranjuez bagian I Allegro con Spirito}

Proses semiosis pada level poietic menghasil makna bagi komposer. Level ini dimulai dari bagaimana seorang komposer memulai proses kreatif. Tentu saja proses kreatif berawal dari pertanyaan siapakah komposer yang akan berkarya. Ia adalah Joaquin Rodrigo. Lahir di Saguto, provinsi Valencia pada tanggal 22
November 1901 (Rodrigo, 1957:iii). Terlahir normal sampai kemudian pada usia tiga tahun mengalami kebutaan yang disebabkan wabah penyakit mematikan. Mulai belajar solfegio, piano dan biola pada usia delapan tahun, lalu melanjutkan studi ke Konsevatori Valencia pada usia lima belas tahun. Ia belajar ilmu harmoni dan komposisi di bawah bimbingan guru Francisco Antich, Erique Goma dan Lopez Chavarri. 
Walaupun kondisi fisiknya terbatas, Rodrigo mampu menciptakan komposisi dengan sub judul Allegro con spirito. Apa yang terjadi dalam diri Rodrigo, yang membuat ia mampu, tidak putus asa, mboten semplah, itulah makna yang terkandung dalam Allegro con spirito.

Proses semiosis pada level neural menghasilkan makna musikal dalam score komposisi Allegro con spirito. Level ini dapat terlihat pada ringkasan dalam tabel matriks dari score komposisi Allegro con spirito. Score ini berisi instrumen, notasi, birama, sukat, tempo dan dinamik. Dalam score, sekurangkurangnya ada 241 makna musikal dihitung dari jumlah birama dan bila 241 birama dikalikan 6 hitungan (dalam bahasa sehari-hari disebut ketukan) setiap birama maka jumlah makna sama dengan 1446 dan bila ditambah dengan birama ke-163 dengan sukat 9/8 menghasilkan jumlah sama dengan 1455 makna musikal. Asumsi-asumsi kuantitatif ini yang kemudian digabung dengan asumsi-asumsi kualitatif niscaya akan menghasilkan makna musikal yang sangat berlimpah. Makna juga terkandung dalam score yang menunjuk pada tonika dan relasi-relasinya. Tonika dimulai dari D Mayor yang mengandung makna musikal senang, dan makna senang ini didukung oleh relasi tanda dengan tanda lainnya dalam hal ini adalah dominant dan subdominant dari tonika D Mayor dalam Allegro con spirito.

Makna lainnya terkandung juga dalam score yang menunjuk pada tanda dinamik. Dinamik yang digunakan dalam komposisi meliputi $p p, p$, $f$, $m f$, ff, cresc, dcresc,. Makna dinamik tidak sulit dan dapat dicari di dalam kamus: $p p$ (pianissimo) bermakna sangat lembut, $p$ (piano) bermakna lembut, $f$ (forte) bermakna kuat, $m f$ (mezzo forte) bermakna agak keras, ff (fortissimo) bermakna keras sekali. Makna tanda dinamik dapat juga dartikan berdasarkan pada posisi dinamik yang diletakan dalam score.

Proses semiosis pada level esthesic dapat dihasilkan dari penonton, musisibahkan komposer. Proses semiosis pada semua level ada keterkaitan hubungan satu sama lain yang meberi makna sebagai fakta musikal bagi komposer, pemain dan penonton. Fakta musikal yang dihasilkan bisa bermakna subjektif ataupun objektif tergantung situasi dan kondisi serta pemahaman, persepsi, interpretasi serta interaksi dari semua level dalam tripartisi. Makna subjektif bagi komposer dan musisi dan penonton adalah semangat, sedang makna objektif adalah semangat pada teks Allegro con spirito.

\section{Penutup}

Makna musikal pada level poietic bagi Rodrigo adalah tidak mudah putus asa, mboten semplah, ramai dan bersemangat seperti Allegro con spirito. Tampak juga dalam level neural, sukat yang stabil bermakna tenang, tonika dimulai dari mayor dan diselesaikan dalam mayor bermakna suasana gembira. Dinamika yang dinamis bermakna semangat dari yang sangat lembu, lembut, kuat, kerasa, hingga keras sekali. Pada level esthesic bagi pemain dan penonton adalah bermakna menggugah semangat seperti Allegro con spirito (allegro $=$ ramai, con sprito $=$ dan bersemangat $)$.

\section{Kepustakaan}

Attali, Jacques, 2009. Noise, The Political Economy of Music, Translation by Brian Massumi. Minneapolis: University of Minneasota Press.

Berger, Arthur Asa, 2005. Tanda-tanda Dalam Kebudayaan Kontemporer Suatu Pengantar Semiotika, diterjemahkan: M. Dwi Marianto dan Sunarto, Yogyakarta: Tiara Wacana Yogya.

Eco, Umberto, 1979. A Theory of Semiotics, Bloomington: Indiana University Press.

Kustap, 2007. "Makna Musik Sampeq Dayak Kenyah Suatu Kajian Semiotik" dalam Jurnal Surya Seni, Vol. 4 No. 2.

Langer, Susanne K., 1953. Feeling and Form A Theory of Art, New York: Charles Scribner's Sons.

Langer, Susanne K., 1957. Problems of Art, New York: Charles Scribner's Sons.

Merriam, Alan P., 1967. The Anthropology of Music, US: Northwestern University.

Nattiez, Jean-Jacques, 1990. Toward A Semiology of Music, translation by Carolyn Abbate. Princeton: Princeton University Press.

Rodrigo, Joaquin, 1957, Concierto De Aranjuez for Guitar and Orchestra. London: Ernes Eulenburg Ltd.

Wahono, Sri dan Kustap, 2007. "Adagio dari Coincierto de Aranjuez untuk Gitar dan 
Orkestra Karya Joaquin Rodrigo: dari Perspektif Semiotika" dalam Resital Jurnal Seni Pertunjukan. Volume 8 No. 1-Juni.

Piliang, Yasraf Amir, 1999. Hipersemiotika: Tafsir Kultural Studies ata Matinya Makna, Bandung: Jalasutra.

Zoest, Aart van, 1993. Semiotika: Tentang Tanda, Cara Kerjanya dan Apa yang Lakukan Dengannya. Jakarta: Yayasan Sumber Agung.

\section{Internet}

Arjan van Baest \& Hans van Drielm, 1995. "The Semiotics of C.S Peirce Applied to Music A matter of Belief". web site:http://comcom.uvt. $\mathrm{nl} / \mathrm{driel} / \mathrm{publica} /$ music

Chandler, Daniel, 1994. "Semiotics for Beginners" web site: http://www.music.indiana.edu/ -ltomlin/ semiotic.html\#top

Gorny, Eugene, 1994. "What is Semiotics?" web site: http://zhurnal.ru/staff/gorny/texts/what is_ semiotics_r.html

Suhor, Charles, 1990. "Semiotics and the English Language Arts" web site: http:/www.indiana.edu/ reading/www/index.html
Wikipedia. (Downloaded on September, 12, 2005), “Meaning” web site: http://en.wikipedia. org/wiki/Meaning

Wikipedia. (Downloaded on September, 12, 2005), "Sign" web site: http://en.wikipedia.org/ wiki/Sign_\%28semiotics\%29

Ryder, Martin. (May 2004) "Semiotics Language and Culture" web site: http://www.chass.utoronto. $\mathrm{ca} / \mathrm{epc} / \mathrm{srb} / \mathrm{srb} /$ archives.html

Stanford Encyclopedia of Philosophy. "Medieval Semiotics" web site: http://www.plato.stanford. edu/fudraising.html

Peirce, Charles Sander. (written: 1894) "What is Sign?" web site:http://www.iupui. edu/\%7Epeirce/web/ep/ep2/ep2book/ch02/ ep2ch2.htm.

Zeman, Jay, 2003. "Peirce's Theory of Signs" web site: www.web.class.ufl.edu/users/jzeman/Peirce_ theory_of_signs.htm\#1

Tagg, Philip, 1999. "Introductory Notes to the Semiotics of Music". web site: www.web.class.ufl. edu/users/jzeman/Peirce_theory_of_signs.htm\#1

Mazzola, Guerino, 2008. "Semiotics of Music" Web Site: http://www.ifi.unizh.ch/mml/musicmedia/ documents/musiksemiotik.pdf 